\title{
Electron number density profiles derived from radio occultation on the CASSIOPE spacecraft
}

Shume, E. B. ; Vergados, P. ; Komjathy, A.; B. Langley, R.; Durgonics, Tibor

Published in:

Radio Science

Link to article, DOI:

10.1002/2017RS006321

Publication date:

2017

Document Version

Peer reviewed version

Link back to DTU Orbit

Citation (APA):

Shume, E. B., Vergados, P., Komjathy, A., B. Langley, R., \& Durgonics, T. (2017). Electron number density profiles derived from radio occultation on the CASSIOPE spacecraft. Radio Science, 52(9), 1190-1199 . https://doi.org/10.1002/2017RS006321

\section{General rights}

Copyright and moral rights for the publications made accessible in the public portal are retained by the authors and/or other copyright owners and it is a condition of accessing publications that users recognise and abide by the legal requirements associated with these rights.

- Users may download and print one copy of any publication from the public portal for the purpose of private study or research.

- You may not further distribute the material or use it for any profit-making activity or commercial gain

- You may freely distribute the URL identifying the publication in the public portal 


\section{Electron number density profiles derived from radio occultation on the CASSIOPE spacecraft}

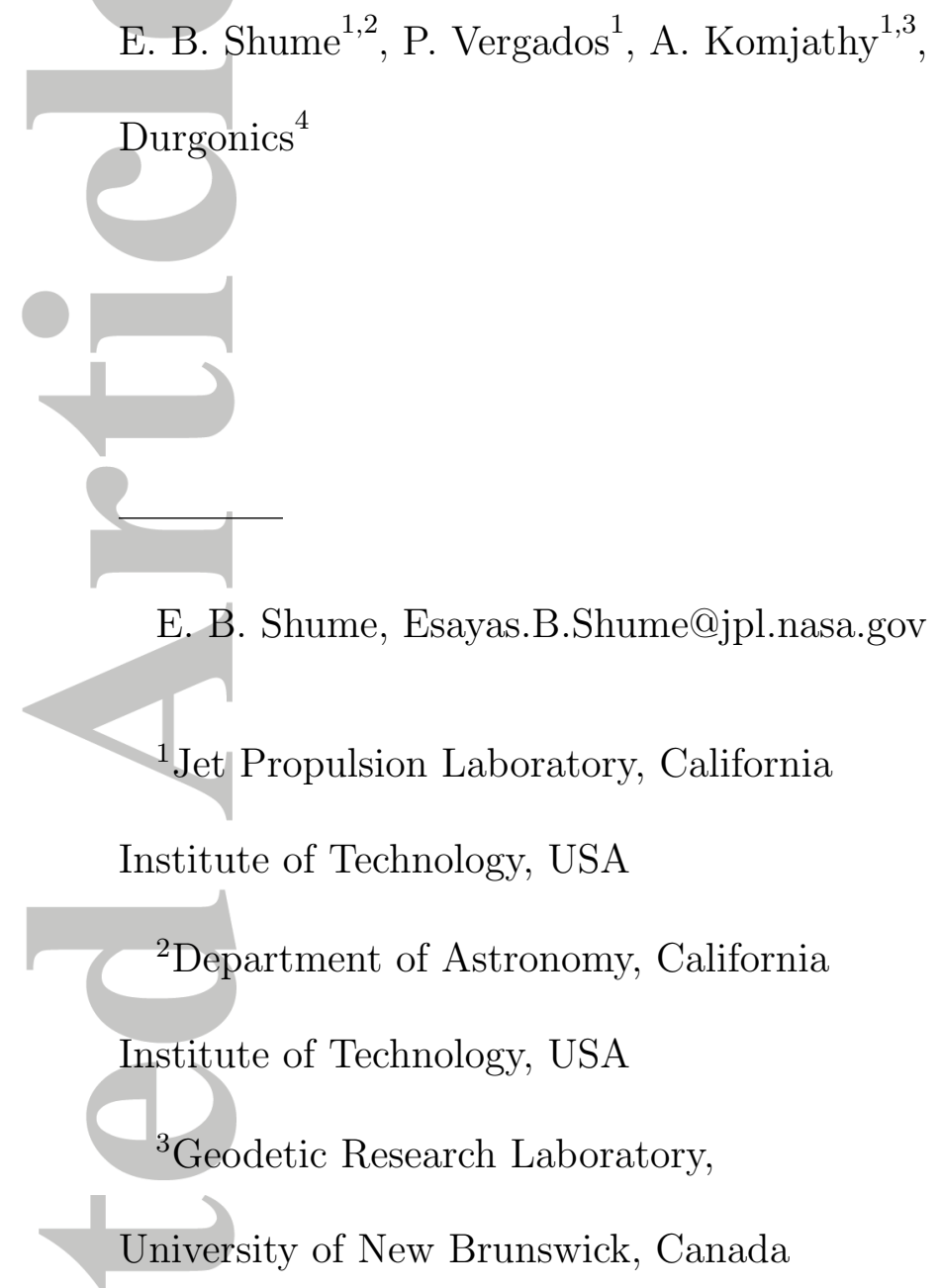

${ }^{4}$ National Space Institute, Technical

University of Denmark, Denmark

This article has been accepted for publication and undergone full peer review but has not been through the copyediting, typesetting, pagination and proofreading process, which may lead to differences between this version and the Version of Record. Please cite this article as doi: 10.1002/2017RS006321

(C)2017 American Geophysical Union. All Rights Reserved. 
Abstract. This paper presents electron number density profiles derived from high resolution Global Positioning System (GPS) radio occultation (RO) observations performed using the Enhanced Polar Outflow Probe (e-POP) payload on the high inclination CAScade, Smallsat and IOnospheric Polar Explorer (CASSIOPE) spacecraft. We have developed and applied a novel inverse Abel transform algorithm on high rate RO total electron content (TEC)

measurements performed along GPS to CASSIOPE radio links to recover electron density profiles. The high resolution density profiles inferred from the CASSIOPE RO are: (1) in very good agreement with density profiles estimated from ionosonde data, measured over nearby stations to the latitude and longitude of the RO tangent points, (2) in good agreement with density profiles inferred from GPS RO measured by the Constellation Observing System for Meteorology, Ionosphere, and Climate (COSMIC), and (3) in general agreement with density profiles estimated using the International Reference Ionosphere (IRI) climatological model. Using both CASSIOPE and COSMIC RO observations, we identify, for the first time, that there exist differences in the characteristics of the electron number density profiles retrieved over landmasses and oceans. The density profiles over oceans exhibit widespread values and scale heights compared to density profiles over landmasses. We provide an explanation for the ocean-landmass discrepancy in terms of the unique wave coupling mechanisms operating over oceans and landmasses.

Keypoints:

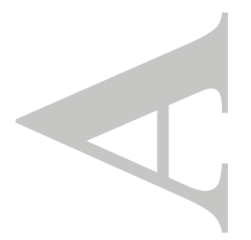

(C)2017 American Geophysical Union. All Rights Reserved. 
- The study provides realistic and high spatial resolution electron density profiles inferred from radio occultation measurements by the CASSIOPE spacecraft using a novel Abel inversion algorithm.

- Utilizing the electron density profiles inferred from CASSIOPE's radio occultation observations, the study provides for the first time distinct properties of density profiles over oceans and landmasses, with a plausible physical explanation for these properties.

- The study provides a valuable electron density data product to be used as input for ionospheric modeling, geospace research, space weather applications, and natural hazard detection.

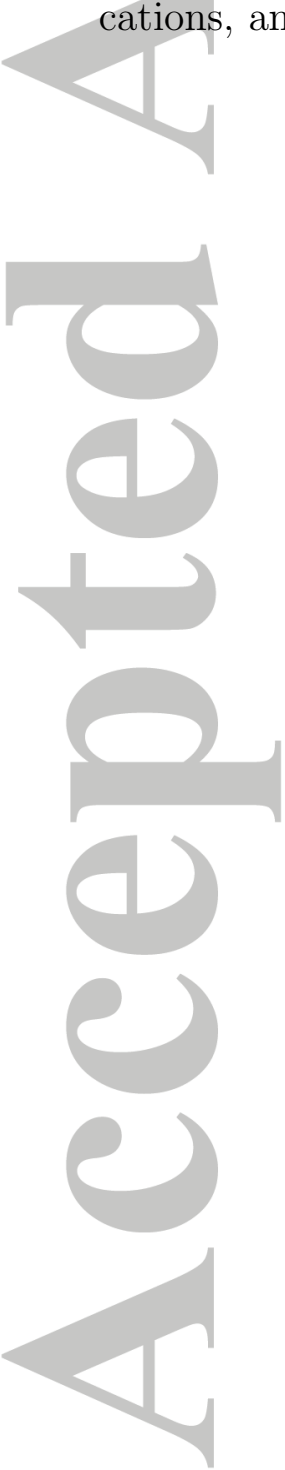




\section{Introduction}

Spatial and temporal inhomogeneities of ionospheric electron number density profiles are modulations by the solar (sunspot) cycle, seasonal and diurnal variations of ionization sources (solar radiation and particle precipitation), chemical and radiative recombination processes, and plasma transport (local and global) drivers [Hargreaves, 1992]. Realistic modeling of ionospheric conductivities, current systems, electric fields, generation of electron density irregularities, and understanding of the three dimensional (3D) plasma transport patterns in the terrestrial ionosphere and magnetosphere require precise and accurate characterization of the spatial and temporal variations of the ionospheric electron density profiles.

Currently, most of our knowledge of the ionospheric electron density depends on measurements performed by incoherent scatter radar (ISR), ionosondes, Global Positioning System (GPS) satellites, rocket and satellite in situ probes as well as ionospheric models (empirical and physics-based).

1. Climatological models such as the International Reference Ionosphere (IRI) [Bilitza et al., 2014] and the Parametrized Ionosphere Model (PIM) [Daniell et al., 1995] provide valuable information about long-term electron density and composition specification of the ionosphere in a 3D global altitude, latitude, and longitude grid. Needless to say that such climatological models have limitations to deliver characterization of rapid spatial and temporal ionospheric variabilities and density gradients.

2. From the perspective of ionospheric measurements, total electron content (TEC) retrieved from differential GPS observables are used to construct valuable two-dimensional

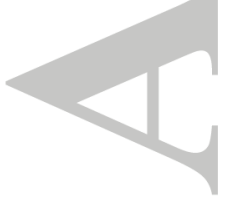

(C)2017 American Geophysical Union. All Rights Reserved. 
(2D) global ionosphere maps (GIMs) approximating the ionosphere as an infinitesimally thin layer at a height of $450 \mathrm{~km}$ [Mannucci et al., 1998; Komjathy et al., 2005]. Despite their limited global coverage, ISR measurements [Farley, 1969] have also contributed high spatial (vertical) and temporal resolution estimates of ionospheric plasma parameters (profiles of density, composition, drifts, etc.).

3. In addition, since April 2006, GPS radio occultation (RO) data from the Constellation Observing System for Meteorology, Ionosphere, and Climate (COSMIC) satellites [Anthes, 2011] and other RO platforms provide good representations and global electron density profile coverage.

On 29 September 2013, the CAScade, Smallsat and IOnospheric Polar Explorer (CASSIOPE) spacecraft [Yau and James, 2015] was launched carrying the GPS Attitude, Positioning, and Profiling (GAP) experiment [Kim and Langley, 2010], offering for the first time the opportunity to perform ionospheric occultations with up to $100 \mathrm{~Hz}$ sampling rate. Never before has an RO mission provided an opportunity for estimation of high resolution electron density profiles. The availability of such high sampling rate observations allowed us to revisit the inverse Abel transform and provide an analytical solution, which we could not do otherwise due to small-scale spatial structures in the ionosphere. High sampling rate for $\mathrm{RO}$ observations is a science requirement for future $\mathrm{RO}$ missions such as the impending COSMIC-2 mission [FormoSat-7/COSMIC-2] enabling the development of new inversion retrieval algorithms such as the one presented here. The availability of high sampling rate ionospheric RO data is key to accurately characterizing the bottom-side ionosphere, where the approximation of the spherical symmetry assumption in the Abel

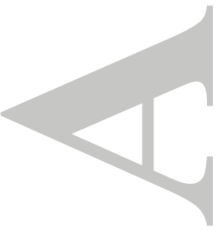

(C)2017 American Geophysical Union. All Rights Reserved. 
inversion transform collapses due to the presence of small-scale spatial and rapid temporal plasma density irregularities.

The CASSIOPE data sets will help us improve our knowledge of the ionospheric electron density profiles and open new avenues to ionospheric research. Specifically, the results provide: (1) realistic and high spatial resolution electron density profiles inferred using a novel Abel inversion algorithm, (2) for the first time distinct properties of electron density profiles over oceans and landmasses, with a plausible physical explanation for these properties, and (3) a valuable electron density data product to be used as input for ionospheric modeling, geospace research, space weather applications, and natural hazard detection. The CASSIOPE spacecraft, a dedicated polar orbiting ionospheric research spacecraft, has an elliptical orbit with an initial perigee of about $325 \mathrm{~km}$ and an initial apogee of about $1500 \mathrm{~km}$. The RO receiver on CASSIOPE has a high sampling rate making it suitable for conducting such investigations. Consequently the results presented in this paper are unique compared to previous GPS-LEO satellite RO studies. In addition, the independent COSMIC RO-inferred peak electron density estimates, which are presented in this paper, have provided supporting proof for the ocean-landmass electron density differences.

Section 2 describes the GPS RO TEC observations retrieved from the CASSIOPE spacecraft, and provides details about the application of the inverse Abel transform to recover electron density profiles from TEC profiles. Section 3 presents examples of density profiles inferred from CASSIOPE RO TEC data, and comparisons of the RO-inferred profiles with density profiles derived from ionosonde observations, the IRI climatological model, and COSMIC RO data. Section 4 uses the CASSIOPE and COSMIC RO observations (C)2017 American Geophysical Union. All Rights Reserved. 
to present landmass and ocean contrasts of the density profiles, together with plausible physical interpretations. Section 5 presents the summary and conclusions.

\section{RO data and techniques of data analysis}

\subsection{GPS RO observations on CASSIOPE}

RO observations provide TEC estimates along the raypath between a GPS satellite and the CASSIOPE spacecraft as a function of the altitude of the raypath tangent point. A tangent point is the raypath's closest approach to the Earth's center. The five GAP GPS receivers, including the $\mathrm{RO}$ receiver, are identical slightly modified off-the-shelf NovAtel OEM4-G2L dual-frequency receivers. GAP utilized off-the-shelf receivers as a cost-savings measure. The RO receiver is fed by a modified NovAtel GPS-702 "pinwheel" antenna.

A Spectrum Microwave 26- $\mathrm{dB}$ low noise amplifier is used between the antenna and the receiver. and The receiver firmware is essentially the one used for terrestrial applications except for the high measurement-output-rate capability. The receiver can be commanded from the ground to supply 20-Hz, 50-Hz or 100-Hz data rate [Kim and Langley, 2010; Shume et al., 2015]. Here, we exploit the 100-Hz sampled data to analytically solve the inverse Abel transform to derive electron density profiles.

\subsection{Inverse Abel transform}

Given ionospheric relative TEC estimates $\left(T_{e c}(s)\right)$ as a function of tangent altitude $(s)$, the inverse Abel transform [Hajj and Romans, 1998] estimates electron density profiles $\left(n_{e}(r)\right)$ as a function of radial distance $(r)$. In a nutshell, the Abel transform and its inverse are transfrom pairs that transform between a ray path distance coordinate and a radial distance coordinate. The inverse Abel transform is represented (assuming spherical

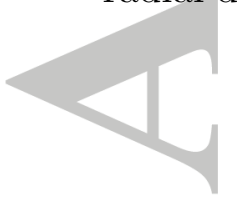

(C)2017 American Geophysical Union. All Rights Reserved. 
symmetry) by:

$$
n_{e}(r)=-\frac{1}{\pi} \int_{r}^{r_{c a}} \frac{d T_{e c}(s)}{d s} \frac{d s}{\sqrt{s^{2}-r^{2}}}
$$

where $d T_{e c}(s) / d s$ is the derivative of the relative TEC with respect to tangent altitude, and the parameter $r_{c a}$ is the radial distance of the CASSIOPE spacecraft from the Earth's center.

Application of the standard integration by parts technique on the integral (equation 1) leads to an analytical expression for electron density profiles as a function of $r$ :

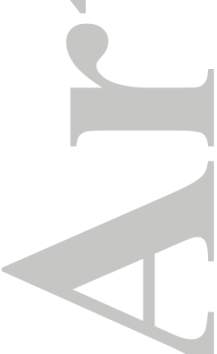

$$
\begin{aligned}
n_{e}(r) & =-\left.\frac{1}{\pi} \frac{d T_{e c}(s)}{d s} \log \left|\frac{s}{r}+\frac{\sqrt{s^{2}-r^{2}}}{r}\right|\right|_{s \rightarrow r} ^{s \rightarrow r_{c a}} \\
& =-\frac{1}{\pi} \sum_{\substack{\text { each } \\
\text { ianer } \\
\text { angents } \\
\text { init1 }}} \frac{\Delta T_{e c}}{\Delta s} \log \left(\frac{s_{i+1}+\sqrt{s_{i+1}^{2}-r^{2}}}{s_{i}+\sqrt{s_{i}^{2}-r^{2}}}\right)
\end{aligned}
$$

Equation 2 is derived using the assumption that functional dependencies can be expressed as a series of linear segments that connect input data points [Weickmann and Jones, 1994]. That is, the TEC parameter can be expressed by a linear equation $T_{e c}(s)=A s+B$, where $A$ and $B$ are constants. Using such an assumption, the second derivative of $T_{e c}(s)$ arising in the integration by parts becomes negligible $\left(d^{2} T_{e c}(s) / d s^{2} \rightarrow 0\right)$ giving rise to the analytic expression of equation 2 to estimate electron density profiles. This is where the novelty of using CASSIOPE observations comes in. The assumption of linearity of functions is satisfied for the present Abel inversion because of the high rate of RO observations (TEC samples) made possible by the CASSIOPE RO receiver.

Using high resolution CASSIOPE RO TEC data, we estimated (not shown here) that the quantity $d^{2} T_{e c}(s) / d s^{2}$ is actually negligible. That means, to estimate $n_{e}(r)$ from $T_{e c}(s)$, the analytical expression (equation 2) can be employed. The inverse Abel integral (equation 1) has also been solved using the quadrature integrator [Hajj and Romans, 
1998]. The algorithm employed here to retrieve $n_{e}(r)$ (based on equation 2) curtails error propagation usually associated with numerical integration schemes. In addition, the availability of high rate $\mathrm{RO}$ observations is vital to accurately characterize the ionospheric bottom-side, where the approximation of the spherical symmetry assumption of the Abel transform fails due to the presence of small-scale plasma density irregularities. Mitigating the spherical symmetric contraints resulting from the Abel transfrom is not the objective of this paper. A modified Abel inversion algorithm for ionospheric diagnostics that overcomes the spherical symmetry assumption of the traditional Abel inversion algorithm has been provided by Hernández-Pajares et al. [2000]. We may use that algorithm for future CASSIOPE profile retrivals.

\section{Electron density profiles derived from GPS RO observations on CASSIOPE}

The RO receiver on the CASSIOPE spacecraft routinely measures GPS pseudorange, carrier phase, and carrier-to-noise-density ratio of L-band signals (L1 $=1.575 \mathrm{GHz}$ and L2 $=1.227 \mathrm{GHz})$. Neglecting the small higher-order terms in the Taylor series expansion of the Appelton-Hartree equation, the differential delay between the L1 and L2 frequencies is proportional to the TEC. The effects of higher-order terms on ionospheric and atmospheric retrievals have investigated by Vergados and Pagiatakis [2010, 2011], for example. GPS RO TEC observations $T_{e c}(s)$, we have used equation 2 to recover electron density profiles. Since we have not determined the differential biases of the RO receiver, the TEC values are all relative. Note that the parameter of interest in equation 2 is the derivative of the TEC, therefore, we do not need to estimate the absolute TEC values for two reasons: a) the differential receiver biases remain constant during the short period of an ionospheric RO pass (5 to 10 minutes), and b) equation (2) only requires the TEC gradients between (C)2017 American Geophysical Union. All Rights Reserved. 
epochs. The values of $T_{e c}(s)$ at all tangent points (including top and bottom boundaries) are specified by the CASSIOPE RO observations and can therefore be readily used in the determination of $n_{e}(r)$ profiles using equation 2.

\subsection{Comparison with density profiles estimated by other techniques}

Figures 1A (14 April 2015), 1B (19 December 2014), and 1C (6 December 2014) show example electron density profiles (red curves) in logarithmic scale recovered from RO relative TEC by applying the inverse Abel transform (equation 2). Note that (1) the $F$ peak altitude in these profiles varies from 350 to $400 \mathrm{~km}$ and (2) the $F$ peak electron densities range from about $1.5 \times 10^{11}$ to $3.0 \times 10^{11} \mathrm{~m}^{-3}$. We have presented these density profiles to demonstrate the application of our inversion algorithm (inverse Abel transform) to retrieve electron density profiles. Because CASSIOPE is a polar orbiting LEO and a single spacecraft, there is a limited number of collocated profiles with other RO missions and ionosonde profiles to validate our electron density retrievals. For comparison purposes, we have shown three representative CASSIOPE RO profiles that are collocated with COSMIC RO profiles and ionosonde measurements. Figures 1A - 1C present collocated COSMIC (blue lines), ionosonde (purple lines), and IRI climatology profiles (green lines) for comparison. The IRI model provides ionospheric information at the location and local time of the CASSIOPE RO measurements. The COSMIC and ionosonde profiles are collocated with the CASSIOPE observations using a temporal window of $<1$ hour and a spatial window of $<300 \mathrm{~km}$. The local times corresponding to the CASSIOPE RO-inferred, ionosonde, COSMIC, and IRI electron density data are shown in Figures 1A

$-1 \mathrm{C}$.

3.1.1. Density profiles from ionosonde observations

(C)2017 American Geophysical Union. All Rights Reserved. 
Figures $2 \mathrm{C}$ and $2 \mathrm{D}$ present the tangent point locations of the density profiles shown in Figures $1 \mathrm{~A}-1 \mathrm{C}$ as a function of geodetic latitude and longitude. The locations of the ionosonde instruments relative to the $\mathrm{RO}$ tangent points are shown in Figure $2 \mathrm{C}\left(\mathrm{FF}^{\text {Iono }}\right.$ Fairford, England, station; red arrow points to the station) and Figure 2D ( $\mathrm{MH}^{\text {Iono }}$ Mohe, China, station; red arrow points to the station). The information about the nearby ionosonde stations and their tangent points (19 December 2014 and 14 April 2015) are color-matched. In our analysis, we consider the ionosonde measurements as the groundtruth and focus our comparisons on the bottom-side ionosphere.

The density profiles derived from ionosonde observations (purple curves in Figures 1A and $2 \mathrm{~B}$ ) are plotted with the density profiles (red curves) inferred from Abel inversion of CASSIOPE RO observations. The ionosonde and the RO observations occurred around the same local time (shown in Figure 1). The electron density profiles are derived from ionosonde observations below the $F$ region peak, and the profiles were completed above the F region peak using Chapman profile fitting [Reinisch and Galkin, 2011]. In both Figures $1 \mathrm{~A}$ and 1B, the density profiles inferred from CASSIOPE RO $N_{e}^{\text {cas }}$ and the profiles inferred from ionosonde observations $N_{e}^{i o n}$ are in excellent agreement below the $F$ peak, $N_{e}^{c a s} / N_{e}^{i o n} \sim 1.0$

\subsubsection{Density profiles inferred from COSMIC RO data}

Electron density profiles derived from COSMIC RO observations are shown in Figures $1 \mathrm{~A}, 1 \mathrm{~B}$, and $1 \mathrm{C}$ (blue curves). The closest in proximity of COSMIC RO electron density profiles to the CASSIOPE RO density profiles that we could find are shown in Figures $2 \mathrm{C}$ and $2 \mathrm{D}$ (tangent points shown by thick black curves). These figures show that the tangent points of COSMIC RO and CASSIOPE RO (colored curves) for 14 April 2015,

(C)2017 American Geophysical Union. All Rights Reserved. 
19 December 2014, and 6 December 2014 are nearly co-located allowing the comparison between the profiles. We observe that (1) in Figure 1A, the COSMIC RO $N_{e}^{\cos }$ and CASSIOPE RO-inferred density profiles are in somewhat good agreement (only on part of the lower $F$ region), especially below the $F$ region peak $N_{e}^{c a s} / N_{e}^{c o s} \sim 1.0,(2)$ in Figure 1B, the two profiles show an almost perfect agreement (the scale height above as well as below the $F$ region peak, $N_{e}^{c a s} / N_{e}^{c o s} \sim 1.0$ ), and (3) in Figure $1 \mathrm{C}$, the COSMIC- and CASSIOPE-inferred profiles agree very well above the $F$ region peak (above $300 \mathrm{~km}$ ).

\subsubsection{IRI density profile specifications}

The green curves in Figures 1A, 1B, and 1C are density profiles estimated by the IRI 2012 climatological model. The IRI electron density $N_{e}^{i r i}$ profiles represent the background ionospheric electron density [Bilitza et al., 2014]. Despite the fact that the IRI-specified density profiles represent long-term averages, the comparisons in Figure 1A (above the $F$ peak), and Figures $1 \mathrm{~B}$ and $1 \mathrm{C}$ (below the $F$ peak) are quite good $\left(N_{e}^{\text {cas }} / N_{e}^{\text {iri }} \sim 1.0\right.$ at limited altitudes).

From the above examples, the profiles inferred from the CASSIOPE RO data are compared well with profiles derived from ionosonde observations, COSMIC RO and the IRI model.

\subsection{Atmospheric scale height estimates}

Figure 1D shows atmospheric scale height $H_{s}$ estimates based on the 14 April 2015, 19 December 2014, and 6 December 2014 CASSIOPE-inferred density profiles. The scale heights were derived by fitting Chapman density profiles [Hargreaves, 1992] to the density profiles inverted from CASSIOPE RO observations. A simplified Chapman profile function, which assumes an isothermal atmosphere and height-independent scale heights, was (C)2017 American Geophysical Union. All Rights Reserved. 
employed. We used the $F$ region peak density and peak altitude values to estimate the scale heights. In the fit, the atmospheric scale height is varied until the Chapman function agrees with the RO-inferred density profile. The black curves in Figure 1D are Chapman profile fits to the density profiles derived from Abel inversions. Evidently, the profiles are characterized by distinct scale heights. Referring to Figures 1A and 1B (red and purple curves), we would like to point out that below the $F$ region peak, the plasma scale height of the ionosonde and Abel inverted profiles appear to show striking similarities.

The atmospheric scale heights resulting from the Chapman fit are $49 \mathrm{~km}, 60 \mathrm{~km}$, and $48 \mathrm{~km}$ for the dates above, respectively. Using the approximate relationship $H_{s p} \sim 2 H_{s}$ [Hargreaves, 1992], the plasma scale height $H_{s p}$ estimates corresponding to the profiles in Figure 1D are $\sim 98 \mathrm{~km}, 120 \mathrm{~km}$, and $96 \mathrm{~km}$, respectively. Similar results were recently reported using an analysis of COSMIC RO data [Wu et al., 2016]. The atmospheric and plasma scale height information could be valuable for modeling electron density profiles in the ionosphere [Verhulst and Stankov, 2014; Wu et al., 2016]. A more rigorous study of scale height estimates has been performed using GNSS occultations [Olivares-Pulido et al., 2016]. This study will be taken into consideration in our future analyses.

\section{Electron density profiles over oceans and landmasses: CASSIOPE RO observations}

When retrieving and analyzing the ensemble of CASSIOPE electron density profiles, we noticed differences in the physical characteristics of the inferred profiles over landmasses and over oceanic regions. Although further analysis and more statistical sampling are required to thoroughly investigate these differences, here we present our preliminary results

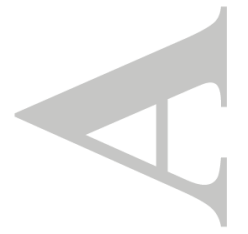

(C)2017 American Geophysical Union. All Rights Reserved. 
to document these observed discrepancies of electron density profiles over landmasses and oceans.

Figures $2 \mathrm{~A}$ and $2 \mathrm{~B}$ show electron density profiles inferred from CASSIOPE RO data over oceans and landmasses, respectively. The information about the geographic locations of the electron density profiles is contained in the RO tangent points. Figures $2 \mathrm{C}$ (oceans) and 2D (landmasses) show the geographic locations (latitude and longitude) of the tangent points (thick colored curves) of RO observations employed for electron density profile estimation.

In Figure 2A, we present example density profiles over oceans corresponding to the dates in the figure. The density profiles and the dates are coded with similar colors. Likewise, the tangent points (latitude and longitude) in Figure 2C are coded with similar colors as the profiles in Figure 2A. Example profiles over landmasses are plotted in Figure 2B. The corresponding tangent points with similar colors are plotted in Figure 2D.

The geomagnetic conditions during the RO measurements (and the inferred electron density profiles shown in Figures $2 \mathrm{~A}$ and $2 \mathrm{~B}$ ) were quiet as indicated by the disturbance storm time $\mathrm{D}_{s t}$ index. The RO measurements occurred during northern hemisphere winter seasons and during similar solar activity conditions.

The aggregate density profiles over oceans (Figure 2A) have distinct characteristics compared to the aggregate profiles over landmasses (Figure 2B). The density profiles over oceans are characterized by large fluctuations of the altitudinal dependence of the density profiles and the electron density scale height. The $F$ region peak density varies from $\sim 2.5 \times 10^{10}$ to $\sim 3 \times 10^{11} \mathrm{~m}^{-3}$. On the other hand, the density profiles over landmasses (Figure 2B) are less variable. For example, the peak $F$ region density values vary from

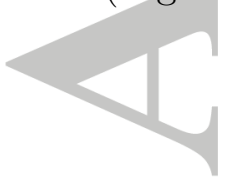

(C)2017 American Geophysical Union. All Rights Reserved. 
$\sim 1.0 \times 10^{11}$ to $\sim 1.7 \times 10^{11} \mathrm{~m}^{-3}$, which is about four times less than the fluctuations over oceans. To the best of our knowledge, such an extensive set of data, which presents contrasting results of electron density profiles over oceans and landmasses, has not been reported in the literature before. However, the topside sounder data on the International Satellites for Ionospheric Studies exhibited large fluctuations in the $F_{2}$ region peak electron density and peak height over oceans compared to those over landmasses [Gulyaeva et al., 2014]. These findings are consistent with the CASSIOPE RO-inferred electron density profiles (Figures $2 \mathrm{~A}$ and $2 \mathrm{~B}$ ).

\subsection{Peak electron density COSMIC GPS RO observations}

This section describes independent COSMIC RO-inferred $F$ region peak electron density data. The COSMIC RO-inferred peak density data are presented in Figure 3 as supplementary supporting evidence for the ocean-landmass contrast of electron density profiles discovered using the CASSIOPE spacecraft observations (Figures $2 \mathrm{~A}$ and $2 \mathrm{~B}$ ). Figure 3 shows one year's (2008) worth of daytime peak density inferred from COSMIC RO measurements [Anthes, 2011]. The histograms in Figure 3A show the daytime peak density over oceans (red) and landmasses (green) in the north Pacific Ocean (the region off the coast of the western United States) and continental North America, respectively. In Figure 3B, the histograms show a comparison of the daytime peak density over North America (green, same as Figure 3A) and north Atlantic Ocean (red). The latitude and longitude of the COSMIC peak density data are enclosed by boxes in Figure 2D (the three boxes). The standard deviations $(\sigma)$ in Figure 3 of peak density (over oceans), $2.15 \times 10^{11} \mathrm{~m}^{-3}$ (north

Pacific) and $2.4 \times 10^{11} \mathrm{~m}^{-3}$ (north Atlantic) are larger than over the North American continent $\left(1.5 \times 10^{11} \mathrm{~m}^{-3}\right)$ indicating that the value of the peak density (over oceans, red) (C)2017 American Geophysical Union. All Rights Reserved. 
shows a larger spread compared to over landmasses (green). The percentages of increase of relative spread of the peak density over oceans (compared to landmasses) are $45 \%$ and $60 \%$ for Figure 3A and Figure 3B, respectively.

\subsection{Surface wind speed estimates: European Centre for Medium-Range Weather Forecasts (ECMWF)}

In this section we present surface wind speed estimates derived from the ECMWF model

[Jet Propulsion Laboratory, 2011], as an attempt to explain a possible physical mechanism for the discrepancy of the magnitude and scale height of electron density profiles over oceans and landmasses shown in Figures 2 and 3.

Surface wind speed estimates from the ECMWF model for the months in 2014 (December), 2015 (January, February, April, and December), and 2016 (January) are displayed in Figures $4 \mathrm{~A}-4 \mathrm{~F}$. The density profiles in Figures $2 \mathrm{~A}$ and $2 \mathrm{~B}$ correspond to these months. The various panels of Figure 4 clearly show a remarkable contrast between the speed of surface winds over ocean and landmass regions. The surface winds over the oceans are characterized by larger magnitude (up to $\sim 25 \mathrm{~m} / \mathrm{s}$ ) compared to surface winds over landmasses (maximum wind magnitude $\sim 5 \mathrm{~m} / \mathrm{s}$ ). From Figure 4 we discern that surface winds over landmasses and oceans differ in strength significantly, and hence the coupling mechanisms of the wind perturbation to the atmosphere for landmass and ocean have different characteristics. In Figure 4, panels $\mathrm{A}_{2}, \mathrm{~B}_{2}$, and $\mathrm{C}_{2}$ present high resolution versions of panels $\mathrm{A}_{1}, \mathrm{~B}_{1}$, and $\mathrm{C}_{1}$.

As an example, a closer look at the north Atlantic Ocean region in Figure 4 shows that the wind patterns can have wind gradients ranging from about $0.2 \frac{\mathrm{m} / \mathrm{s}}{\mathrm{m}}$ to $0.6 \frac{\mathrm{m} / \mathrm{s}}{\mathrm{m}}$. The wind gradients do not have a preferred direction; they are rather random indicating that (C)2017 American Geophysical Union. All Rights Reserved. 
the ocean surfaces are rich in wind gradients (compared to landmasses) perhaps making them more likely for launching atmospheric waves into the region aloft.

\subsection{Physical mechanisms}

What are the possible physical mechanisms that could cause the ocean/landmass discrepancies of the density profiles in Figures 2A and 2B? Wind circulation patterns and ocean-atmosphere-ionosphere wave coupling/decoupling could be possible mechanisms for explaining the characteristics of the electron density profiles shown in these figures as well as the statistical results in Figure 3.

In a recent paper, Godin et al. [2015] presented a physical justification for the coupling of infragravity waves (IGWs) into the upper atmosphere. They reported that (1) at frequencies below about $3 \mathrm{mHz}$ (transition frequency), IGWs continuously radiate energy into the upper atmosphere in the form of acoustic gravity waves, and (2) utilizing ionospheric observations and estimates of the fluxes of the mechanical energy and momentum from the deep ocean, they have concluded that acoustic-gravity waves of oceanic origin may have an observable impact on the upper atmosphere.

Following Godin et al. [2015], Zabotin et al. [2016] have reported experimental evidence that IGWs are a major source of atmospheric wave activity in the thermosphere. Using several months of observations, they have demonstrated large and statistically significant correlation of the variations of the spectral amplitude of IGWs and atmospheric gravity waves (AGWs) over a broad range of frequencies and altitudes. Figures 4A - 4F consistently show large-magnitude surface winds over oceans compared to landmasses indicating

that IGWs associated with the oceans are likely to regularly emit energy into the upper atmosphere.

(C)2017 American Geophysical Union. All Rights Reserved. 
The above discussion indicates that ocean-surface-generated IGWs are a constant source of AGWs. At thermospheric altitudes (above about $150 \mathrm{~km}$ ), electrons are magnetized and ions are coupled with the neutral atmosphere (wind fields of AGWs, in this case). In this scenario, AGWs are capable of polarizing the ionospheric plasma. Consequently, motional electromotive force or the dynamo electric field builds up to maintain plasma quasi-neutrality. The polarity of the electric field mirrors the polarity of the polychromatic

AGWs [Shume et al., 2014]. Depending on the polarity and strength of the dynamo field, the dynamo field may converge or disperse the plasma along the path of the L-band GPS signals received by CASSIOPE's RO receiver. These dynamics cause the magnitude of the TEC along the path of the GPS signal to fluctuate, which ultimately affects the electron density profiles over oceans shown in Figure 2A.

\section{Summary and conclusions}

This paper formally presents for the first time electron number density profiles estimated from GPS RO measurements provided by the high-inclination CASSIOPE spacecraft, which was launched into a polar orbit on 29 September 2013 to study the polar ionospheric region. We have applied a novel inverse Abel transform technique for processing the highresolution $\mathrm{RO}$ data to recover electron density profiles.

Comparisons with independent electron density measures have shown that: (1) The density profiles derived from the CASSIOPE RO measurements are in very good agreement with density profiles estimated from ionosonde observations (which were nearly co-located with the RO tangent points), (2) in good agreement with COMSIC-inferred density profiles, and (3) in general agreement with IRI climatological profiles.

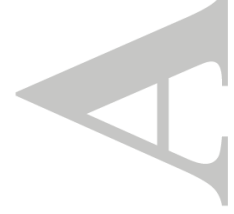

(C)2017 American Geophysical Union. All Rights Reserved. 
We have shown for the first time that the electron density profiles inferred from CASSIOPE RO observations have unique features over oceans and landmasses. Compared to the density profile estimates over landmasses, the density profiles over oceans are characterized by large fluctuations of the height-dependence of the density profiles, the electron density scale height, and the $F$ region peak electron density. These signatures are also evident in COSMIC RO-inferred electron density estimates. A probable explanation for this discrepancy has been provided in terms of electron density restructuring due to the distinct properties of the surface winds (over oceans and landmasses), ocean-atmosphereionosphere coupling (the radiation of energy by the IGWs into the overhead atmospheric region and constantly generating AGWs), and dynamo electric field generation.

Acknowledgments. The research was carried out at the Jet Propulsion Laboratory, California Institute of Technology, under a contract with NASA. The authors would like to thank NASA Headquarters, the ROSES 2014/A.26 GNSS Remote Sensing Science Team Program (NRA NNH14ZDA001N-GNSS). RBL acknowledges financial support from the Natural Sciences and Engineering Research Council (NSERC) of Canada and the Canadian Space Agency (CSA), NSERC, and the University of Calgary supported development of the GAP instrument and the archiving and distribution of GAP data: http://esoc-sdpc.phys.ucalgary.ca. The electron density data inferred from COSMIC RO were downloaded from http://cdaac-www. cosmic.ucar.edu/. The International Reference Ionosphere (IRI) model density profiles were obtained from http://iri.gsfc.nasa.gov/. Surface wind estimates of the ECMWF model were obtained from ftp://ftp.nodc.noaa.gov. The ionosonde data was downloaded from

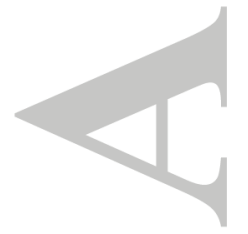

(C)2017 American Geophysical Union. All Rights Reserved. 
the Global Ionospheric Radio Observatory: http://giro.uml.edu/. We thank Bodo Reinisch and Ivan Galkin for providing the ionosonde data.

\section{References}

Anthes, R. A. (2011): Exploring Earth's atmosphere with radio occultation: contributions to weather, climate and space weather, Atmos. Meas. Tech., 4, 1077-1103, doi:10.5194/amt-4-1077-2011.

Bilitza, D., D. Altadill, Y. Zhang, C. Mertens, V. Truhlik, P. Richards, L.-A. McKinnell, and B. Reinisch (2014), The International Reference Ionosphere 2012 - a model of international collaboration, J. Space Weather Space Clim., 4 (2014) A07 doi:10.1051/swsc/2014004.

Daniell Jr., R. E., L. D. Brown, D. N. Anderson, M. W. Fox, P. H. Doherty, D. T. Decker, J. J. Sojka, and R. W. Schunk (1995), Parameterized ionospheric model: A global ionospheric parameterization based on first principles models, Radio Sci., 30(5), 1499-1510, doi:10.1029/95RS01826.

Farley, D. T. (1969), Faraday rotation measurements using incoherent scatter, Radio Sci., 4(2), 143-152, doi:10.1029/RS004i002p00143.

FormoSat-7/COSMIC-2, https://directory.eoportal.org/web/eoportal/ satellite-missions/f/formosat-7\#foot $50 \% 29,2002$.

Godin, O. A., N. A. Zabotin, T. W. Bullett (2015), Acoustic-gravity waves in the atmosphere generated by infragravity waves in the ocean, Earth, Planets and Space, 67:47, doi:10.1186/s40623-015-0212-4.

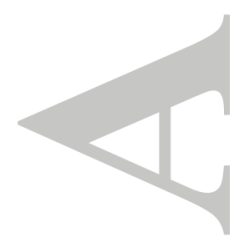

(C)2017 American Geophysical Union. All Rights Reserved. 
Gulyaeva, T. L., F. Arikan, M. Hernandez-Pajares, and I. S. Veselovsky (2014), Northsouth components of the annual asymmetry in the ionosphere, Radio Sci., 49, 485-496, doi:10.1002/2014RS005401.

Hajj, G. A., and L. J. Romans (1998), Ionospheric electron density profiles obtained with the Global Positioning System: Results from the GPS/MET experiment, Radio Sci., 33(1), 175-190, doi:10.1029/97RS03183.

Hargreaves, J. K. (1992), The Solar-Terrestrial Environment: An Introduction to Geospace, Cambridge University Press, Cambridge, UK.

Hernández-Pajares, M., J. M. Juan, and J. Sanz, Improving the Abel inversion by adding ground GPS data to LEO radio occultations in ionospheric sounding, Geophy. Res. Lett, Vol 27(16), 2473-2476, 15 August 2000.

Jet Propulsion Laboratory (2011), OSTM/Jason-2 Products Handbook, OSMT-29-1237, Issue: 1 rev 8, Pasadena, CA, USA.

Kim, D and Langley, R. B. (2010), The GPS attitude, positioning, and profiling experiment for the enhanced polar outflow probe platform on the CAnadian CASSIOPE satellite, Geomatica, Vol. 64. No. 2, 233 - 243.

Komjathy, A., L. Sparks, B. D. Wilson, and A. J. Mannucci (2005), Automated daily processing of more than 1000 ground-based GPS receivers for studying intense ionospheric storms, Radio Sci., 40, RS6006, doi:10.1029/2005RS003279.

Mannucci, A. J., B. D. Wilson, D. N. Yuan, C. H. Ho, U. J. Lindqwister, and T. F. Runge (1998), A global mapping technique for GPS-derived ionospheric total electron content measurements, Radio Sci., 33(3), 565-582, doi:10.1029/97RS02707.

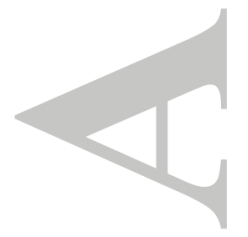

(C)2017 American Geophysical Union. All Rights Reserved. 
Oliváres-Pulido, G., M. Hernández-Pajares, A. Aragón-Angel, and A. Garcia-Rigo (2016), A linear scale height Chapman model supported by GNSS occultation measurements, J. Geophys. Res. Space Physics, 121, 7932-7940, doi:10.1002/2016JA022337.

Reinisch, B.W. and Galkin, I.A., Global Ionospheric Radio Observatory (GIRO) (2011), Earth Planet Space, 63, 377-381, doi:10.5047/eps.2011.03.001.

Shume, E. B., F. S. Rodrigues, A. J. Mannucci, and E. R. de Paula (2014), Modulation of equatorial electrojet irregularities by atmospheric gravity waves, J. Geophys. Res. Space Physics, 119, 366-374, doi:10.1002/2013JA019300.

Shume, E. B., Komjathy, A., Langley, R. B., Verkhoglyadova, O., Butala, M. D. and Mannucci, A. J. (2015), Intermediate-scale plasma irregularities in the polar ionosphere inferred from GPS radio occultation. Geophys. Res. Lett., 42, 688-696, doi: 10.1002/2014GL062558.

Vergados, P., and S. D. Pagiatakis (2010), First estimates of the second-order ionospheric effect on radio occultation observations, J. Geophys. Res., 115, A07317, doi:10.1029/2009JA015161.

Vergados, P., and S. D. Pagiatakis (2011), Latitudinal, solar, and vertical variability of higher-order ionospheric effects on atmospheric parameter retrievals from radio occultation measurements, J. Geophys. Res., 116, A09312, doi:10.1029/2011JA016573.

Verhulst, T., and S. M. Stankov (2014), Evaluation of ionospheric profilers using topside sounding data, Radio Sci., 49, 181-195, doi:10.1002/2013RS005263.

Weickmann, A. and R. M. Jones (1994), A FORTRAN program for performing Abel transform, NOAA Technical Memorandum ERL ETL-224, NOAA Environmental Technology Laboratory, Boulder, Colorado.

(C)2017 American Geophysical Union. All Rights Reserved. 
Wu, M. J., P. Guo, N. F. Fu, T. L. Xu, X. S. Xu, H. L. Jin, and X. G. Hu (2016), Topside correction of IRI by global modeling of ionospheric scale height using COSMIC radio occultation data. J. Geophys. Res. Space Physics, 121, 5675-5692, doi: 10.1002/2016JA022785.

Yau, A.W. and H.G. James (2015), CASSIOPE Enhanced Polar Outflow Probe (e-POP) Mission Overview, Space Sci. Rev. (2015) 189:3-14 doi:10.1007/s11214-015-0135-1

Zabotin, N.A., O. A. Godin, and T. W. Bullett (2016), Oceans are a major source of waves in the thermosphere, J. Geophys. Res. Space Physics, 121, 3452-3463, doi:10.1002/2016JA022357.
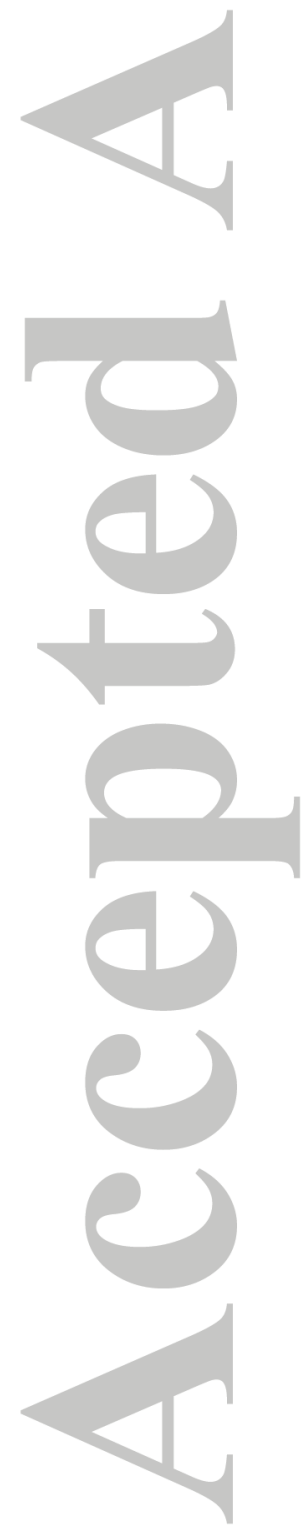

(C)2017 American Geophysical Union. All Rights Reserved. 

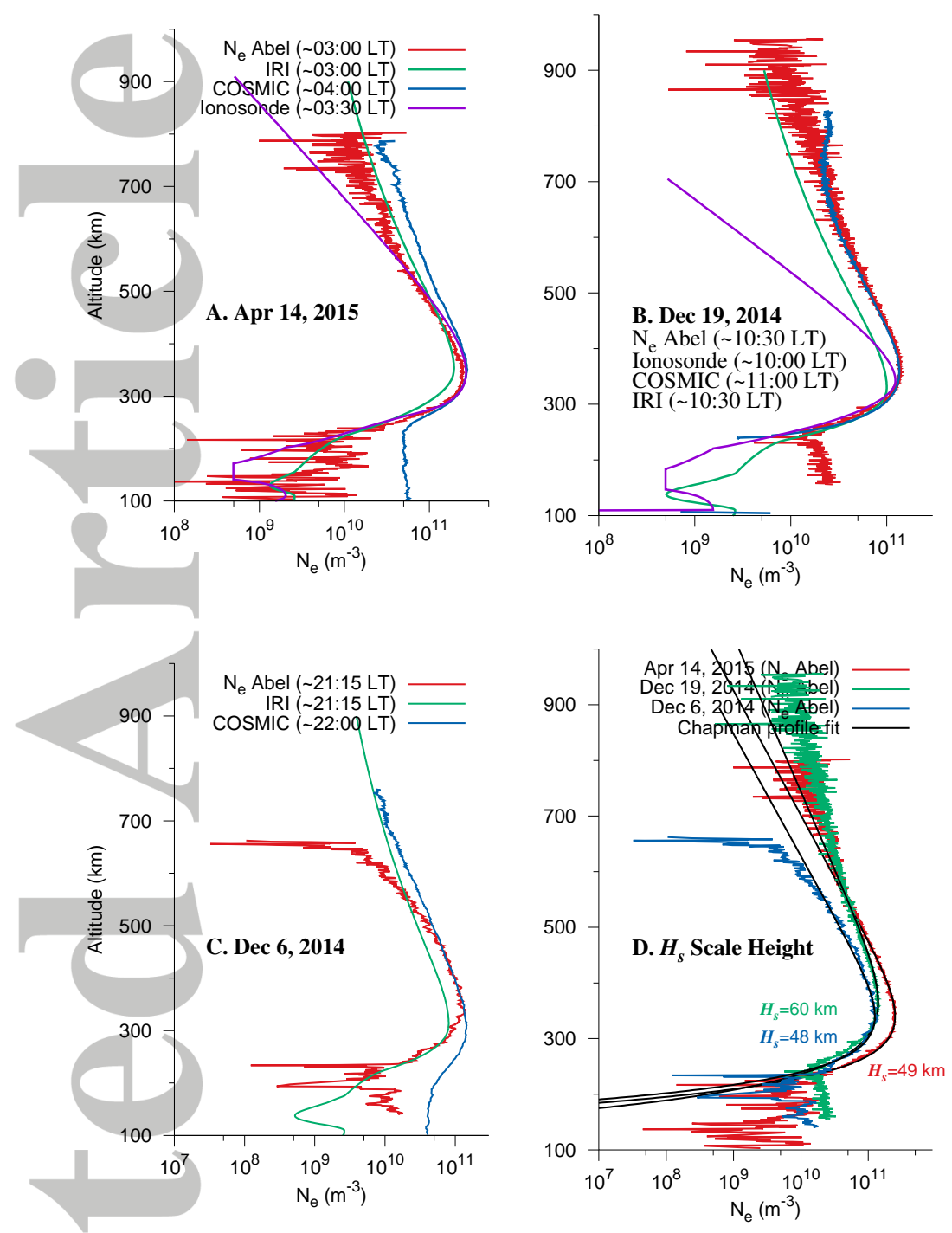

Figure 1. Number density profiles: (A). Density profiles derived from CASSIOPE RO and comparison with density profiles derived from ionosonde data, density profiles inferred from COSMIC RO data, and the IRI model for 14 April 2015. (B) Same as (A) but for 19 December 2014. (C) Same as (A) and (B) but for 6 December 2014 and the CASSIOPE RO-inferred density profiles are compared with ionosonde data and the IRI model. (D) Atmospheric scale height $H_{s}$ derived by fitting simplified Chapman density profiles to the profiles inferred from CASSIOPE $\mathrm{RO}$. 

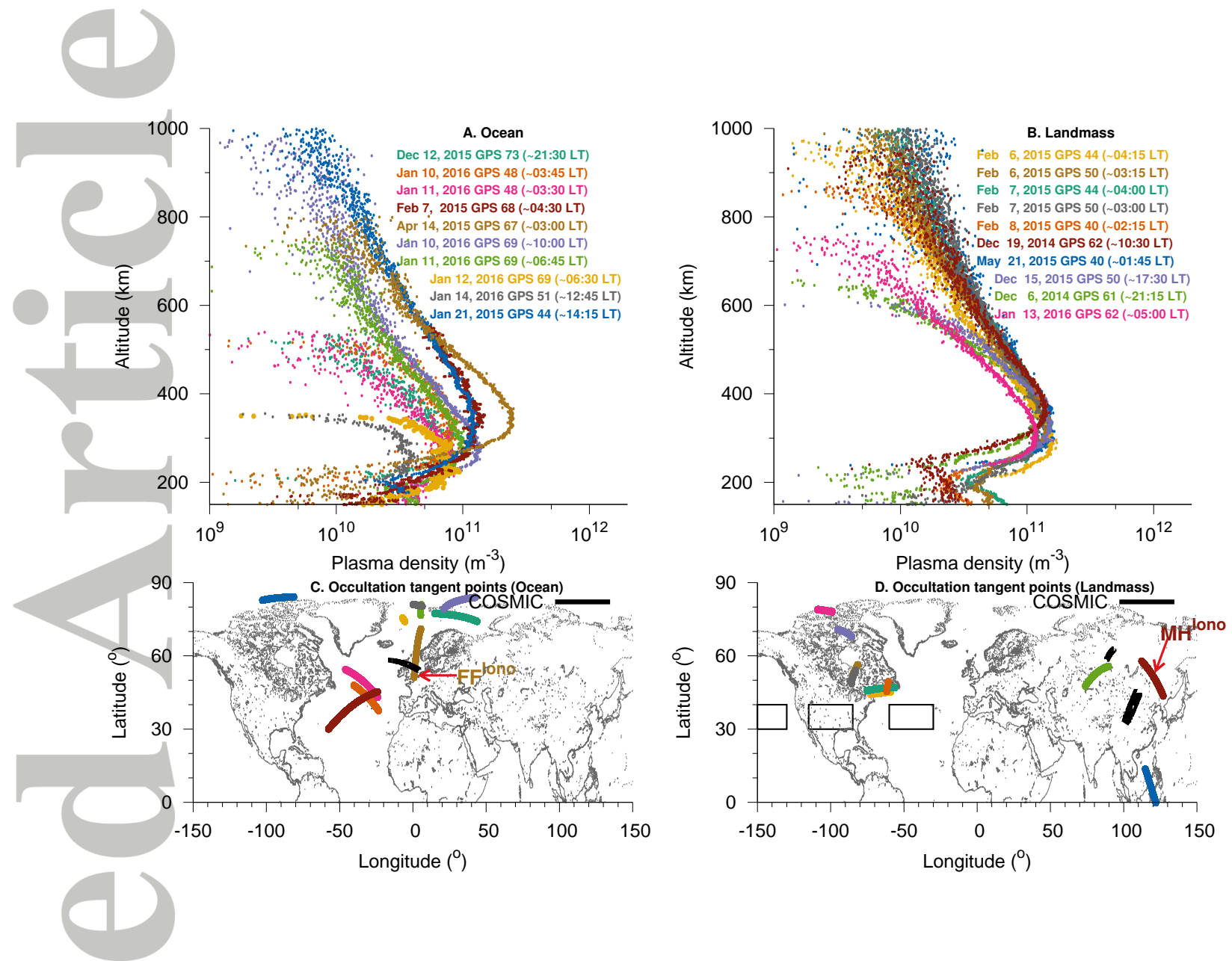

Figure 2. (A) Density profiles inferred from CASSIOPE RO data over oceans for a selection of occultations of various GPS satellite space vehicle numbers. (B) Density profiles inferred from CASSIOPE RO data over landmasses. (C) The tangent points of the radio occultations over oceans. The tangent points and the corresponding density profiles in (A) has similar colors. (D) Same as (C) but over landmasses. The ionosonde stations used for comparison are shown as $\mathrm{FF}^{\text {Iono }}$ (panel C) and $\mathrm{MH}^{\text {Iono }}$ (panel D). Tangent points of the COSMIC RO observations are shown in black in panels (C) and (D).

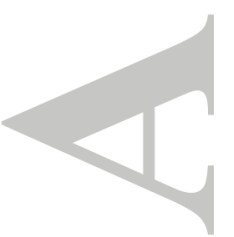

(C)2017 American Geophysical Union. All Rights Reserved. 

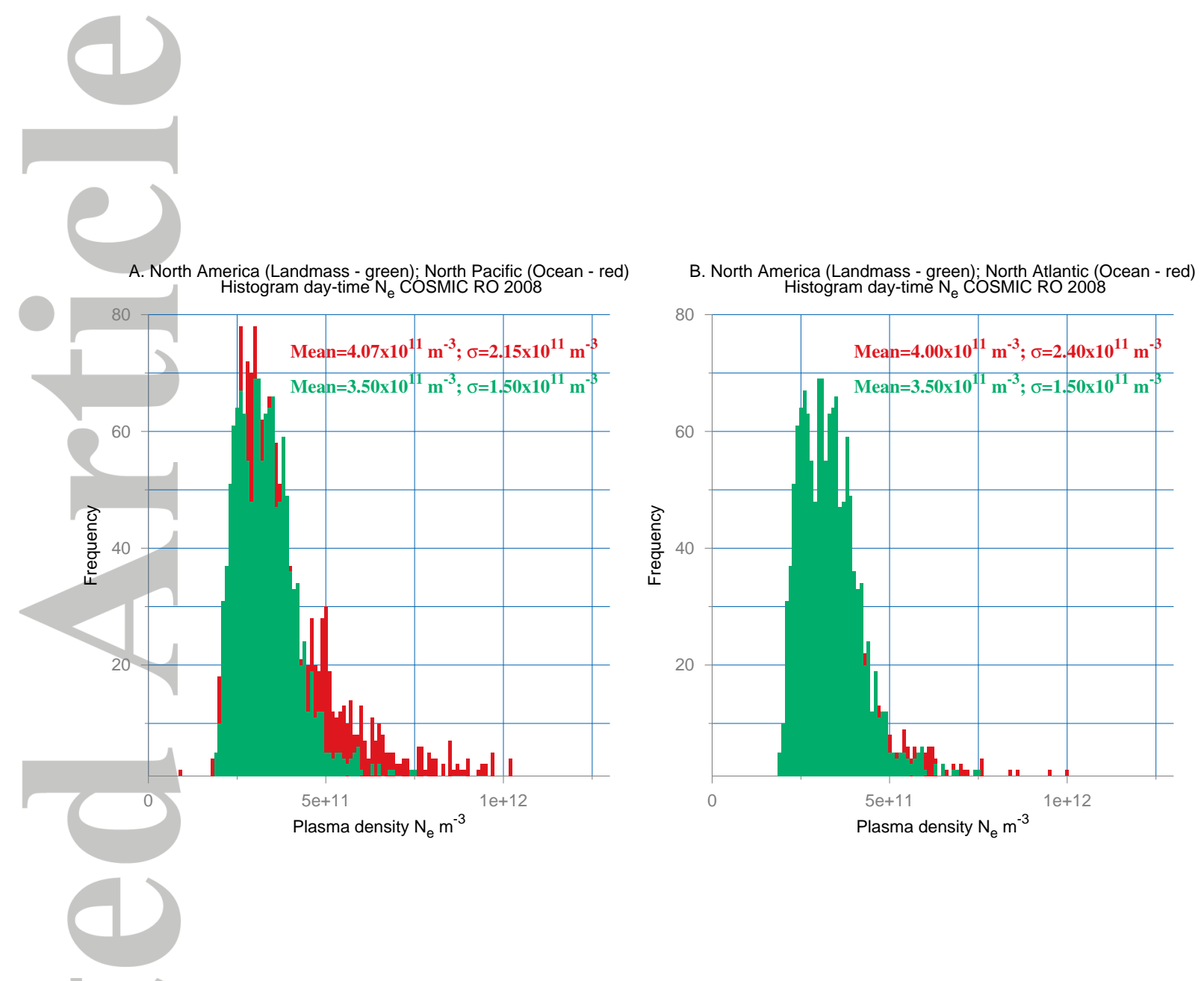

Figure 3. (A) Histogram of daytime peak electron density estimates from COSMIC RO over northern Pacific Ocean (red) and North American continent (green). (B) Same as over North Atlantic Ocean (red), and North American continent (green). The green histogram (peak density over the North American continent) is identical for both panels A and B. The latitude and longitude of the COSMIC peak density data are enclosed by boxes in Figure 2D (three boxes).

(C)2017 American Geophysical Union. All Rights Reserved. 
(s/w) pəəds

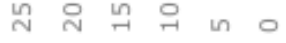

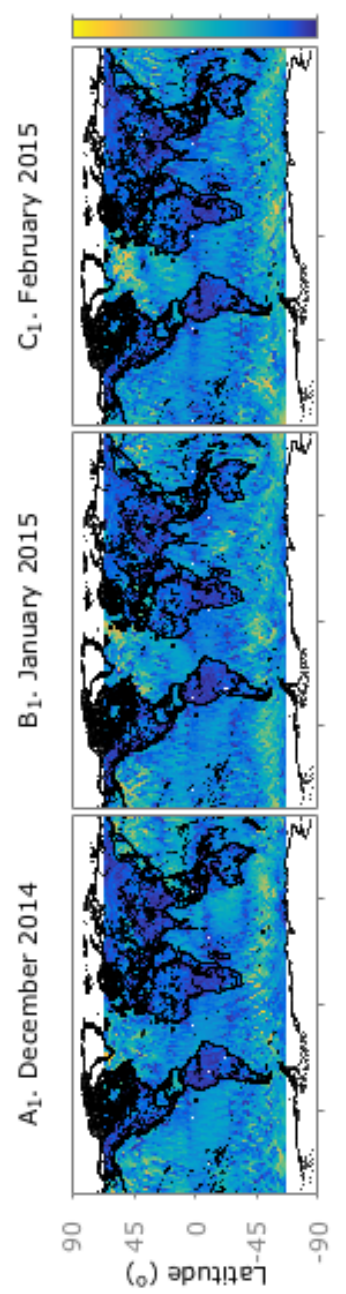

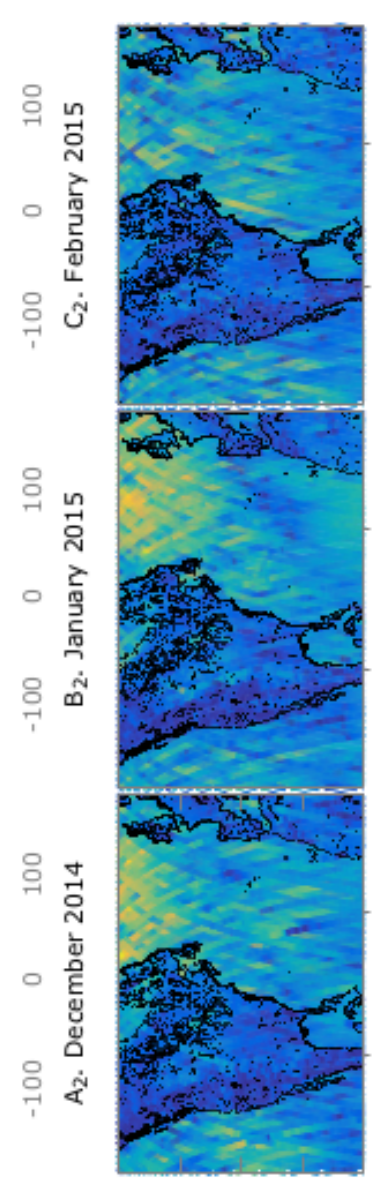

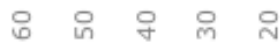

(。) әрпา!ฺฺา

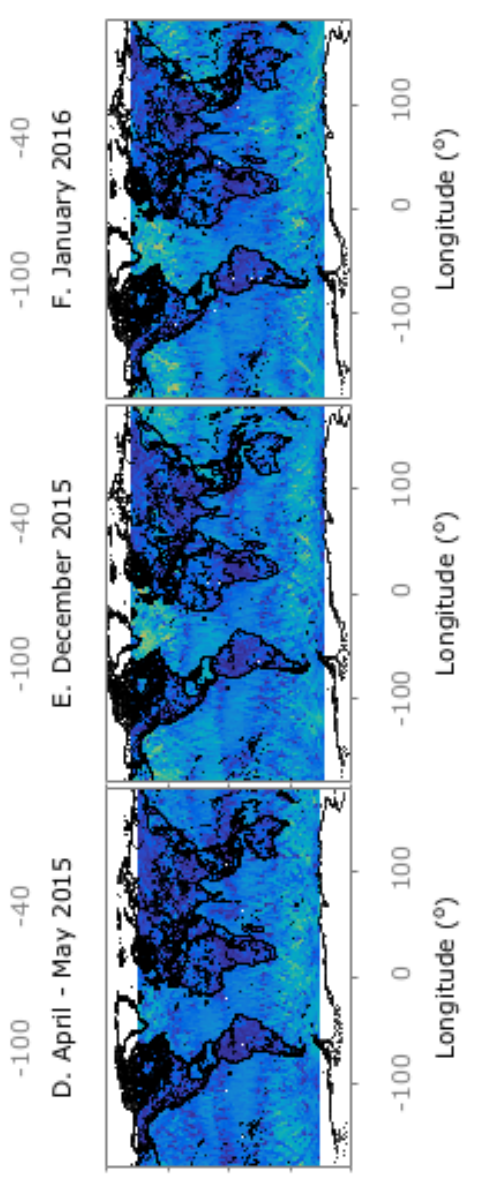

ค ๒

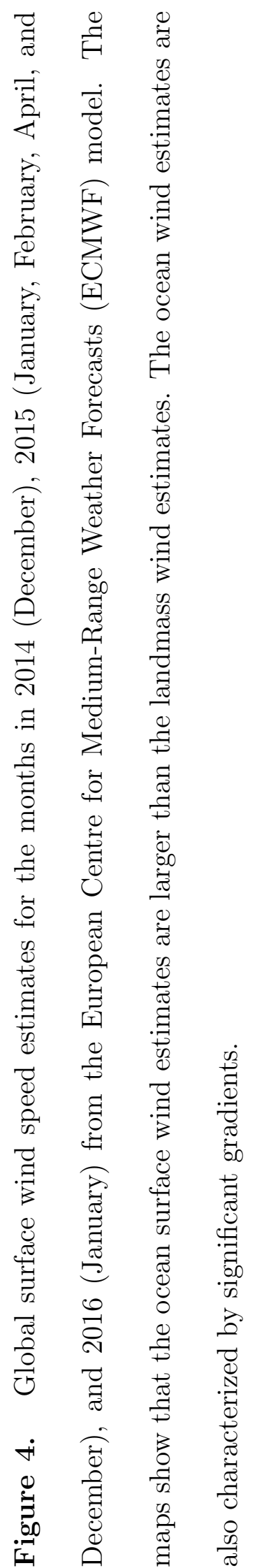

(C)2017 American Geophysical Union. All Rights Reserved. 